\title{
Ameloblastic carcinoma of the mandible
}

Purmal $K^{1}$, Alam $M K^{2}$, Pohchi $A^{3}$, Rahman $S A^{4}$

\begin{abstract}
:
Ameloblastic carcinoma is a highly malignant tumour and requires aggressive treatment. This case report describes an aggressive ameloblastic carcinoma that infiltrated the mandible. Mandibulectomy with right functional radical neck dissection and left supra omohyoid dissection was followed by primary reconstruction with a single free vascularised fibula flap. The postoperative course was uneventful. The 2 year regular follow up revealed no signs of recurrent tumour or metastasis. Future reporting of this rare condition is encouraged in lieu of limited information in its clinical course and prognosis.
\end{abstract}

Keywords: ameloblastic carcinoma; mandibulectomy; radical neck dissection; malignant tumour; metastasis

\section{Introduction}

Ameloblastoma is the most common epithelial odontogenic tumour, representing $1 \%$ of all oral neoplasia with incidence of $80 \%$ in the mandible and $20 \%$ in the maxilla. ${ }^{1}$ This benign neoplasma is locally invasive and shows considerable tendency to recur, but rarely behaves aggressively or shows metastatic dissemination. ${ }^{2}$ Malignant ameloblastoma on the other hand has a typical benign histological appearance but gives rise to nodal or pulmonary metastasis. Both the primary and metastatic lesions retain their benign histologic appearances. Therefore the ability of ameloblastoma to metastasize cannot be predicted by the histology alone. . $^{34}$

Ameloblastic carcinoma which is different entity form malignant ameloblastoma is a rare malignant odontogenic tumour. ${ }^{5}$ In fact in 2005, The World Health Organization have reclassified odontogenictumours and defined it as anodontogenic malignancy that combines the histological features of ameloblastoma with cyctologicatypia, even in the absence of metastases. It may develop de no vo (primary type) or by malignant transformation of an ameloblastoma (secondary type) with a distinction between intraosseous and periphery ameloblastoma. ${ }^{6}$ Ameloblastic carcinoma shows many histologic

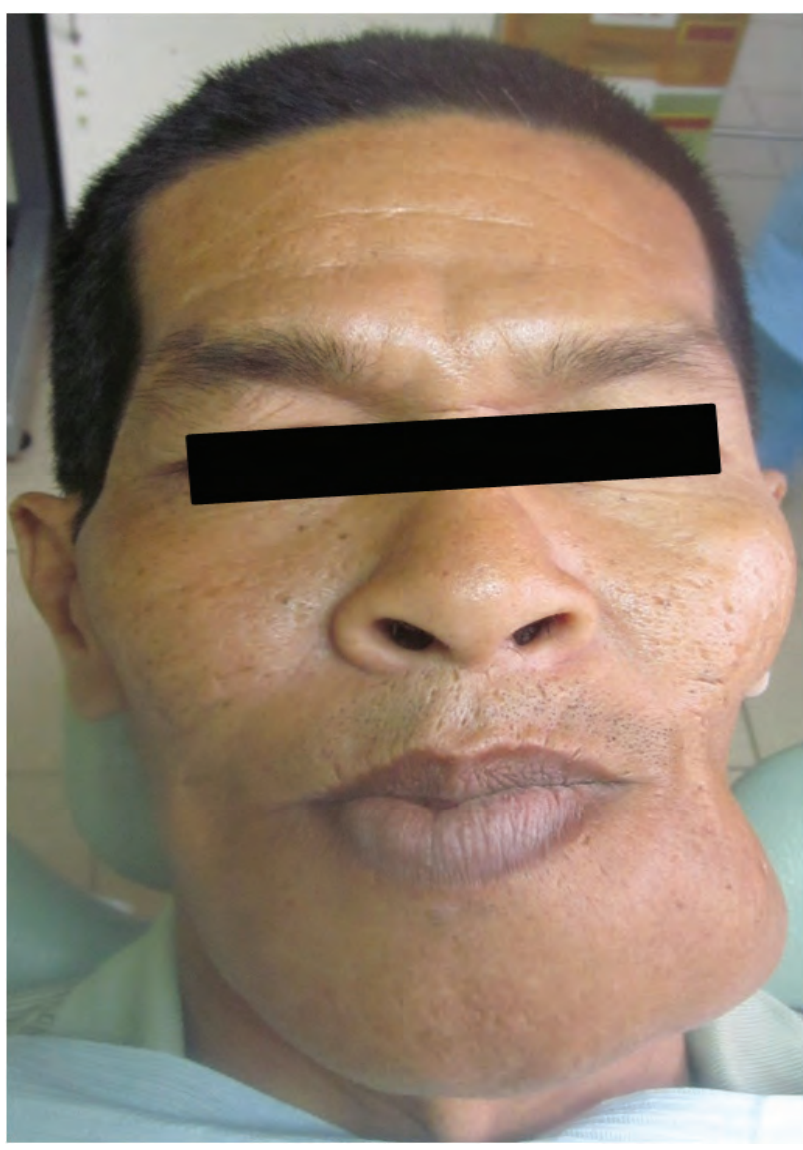

Figure 1. Extra oral presentation of the swelling.

1. Kathiravan Purmal, Resident, Oral and Maxillofacial surgery Department,

2. Mohammad Khursheed Alam, Senior Lecturer, Orthodontic Unit.

3. Abdullah Pohchi, Senior Lecturer, Oral and Maxillofacial surgery Department.

4. Shaifulizan Abdul Rahman, Senior Lecturer, Oral and Maxillofacial surgery Department. School of Dental Science, Universiti Sains Malaysia, Kota Bharu, Kelantan, Malaysia.

Corresponds to: Dr. Mohammad Khursheed Alam, Orthodontic Unit, School of Dental Science, Universiti Sains Malaysia. Kubang Kerian 16150, Kota Bharu, Kelantan, Malaysia. Email: dralam@gmail.com,dralam@usm.my. 


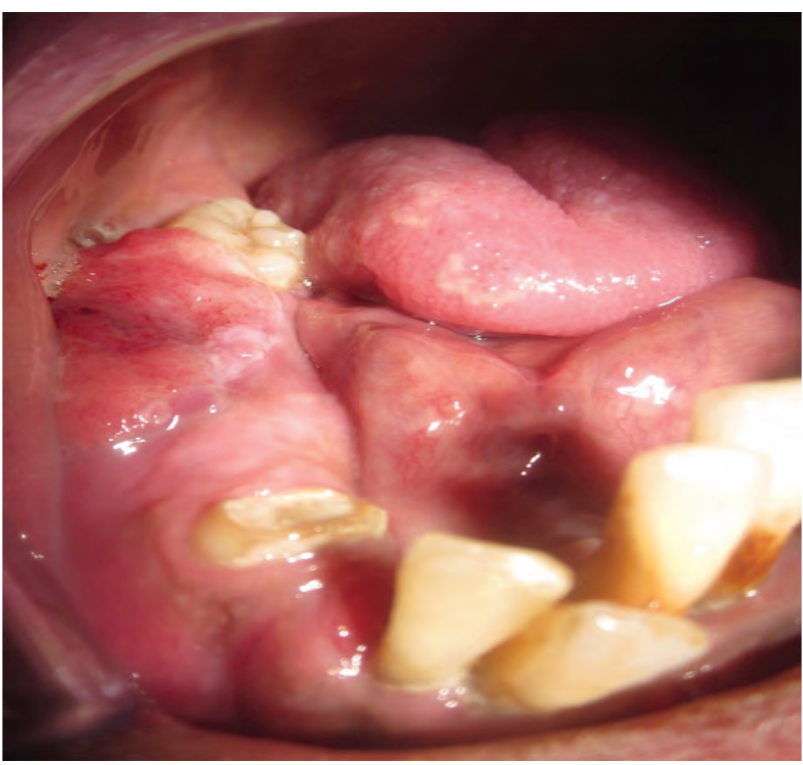

Figure 2. Right side of the lesion.

features of malignancy like dysplasia, increased mitosis, and infiltration of surrounding tissues. However the common features of ameloblastoma like having epithelium in which the basal cells contains columnar or palisaded cells that have a tendency for the nucleus to move from the basement membrane to the opposing end of the cell (reverse polarization) is still present. The epithelium is also known to in the form of islands, strands and medullary arrangements against a background stroma of fibrous connective tissue (follicular pattern) or the epithelium proliferates in a mesh arrangement (plexiform pattern). Clinical presentation of this lesion is the rapid growth, causing pain and may even perforate the cortex. Although rare, these lesions have been known to metastasize mostly to the lung or regional lymph nodes. ${ }^{7}$

\section{Case Report}

A 53 year old Malay fisherman came to the School of Dental Sciences University Sains Malaysia with complaints of swelling in the lower jaw. He had first noticed the swelling about 6 months ago. The swelling has been increasing in size with bilateral lower lip parathesia. It was also associated with pain and trismus.

His significant medical history includes pulmonary tuberculosis diagnosed one year ago. He has since completed the regime of anti-tuberculosis drugs and currently on regular follow-up with the respiratory team.

Clinical examination revealed a fit man with no signs and symptoms elsewhere. There was a bony hard swelling from the right ramus to the left ramus. The size of the swelling was $6 \mathrm{~cm}$ by $5 \mathrm{~cm}$. The overlying

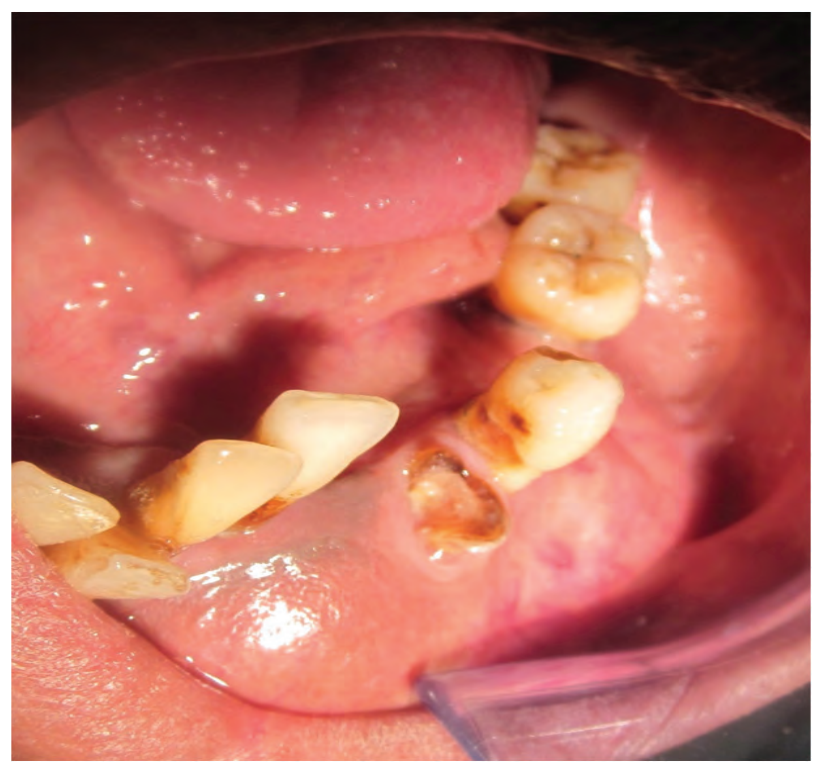

Figure 3. Left side of the lesion.

skin was normal and not fixed to the lesion (Figure 1). There was reduced mouth opening about $3 \mathrm{~cm}$.

On the neck the right submandibular lymph nodes (Level I) and right upper cervical lymph nodes (Level II) were palpable. The size of both the lymph nodes was $1 \mathrm{~cm}$ by $1 \mathrm{~cm}$. The lymph nodes were not tender or fixed to the overlying skin. The bony lesion had perforated the oral mucosa of the right side which is highly suggestive of malignancy (Figure 2 and 3 ). Intraoral examination showed a partial edentulous arch with mobile (grade 3) teeth. Bony expansion was evident bilaterally.

Orthopanthomogram radiograph showed a multilocularosteolytic lesion with distinct margin extending from right to the left angle of mandible (Figure 4). There is resorption of root of lower first left molar in the mandible. No lesion detected in the maxilla. There is multiple retain roots and vertical bone loss around the teeth present.

The posterior anterior chest radiograph shows left upper lobe fibrotic changes (Figure 5).

CT scans of from the base of skull to the abdomen

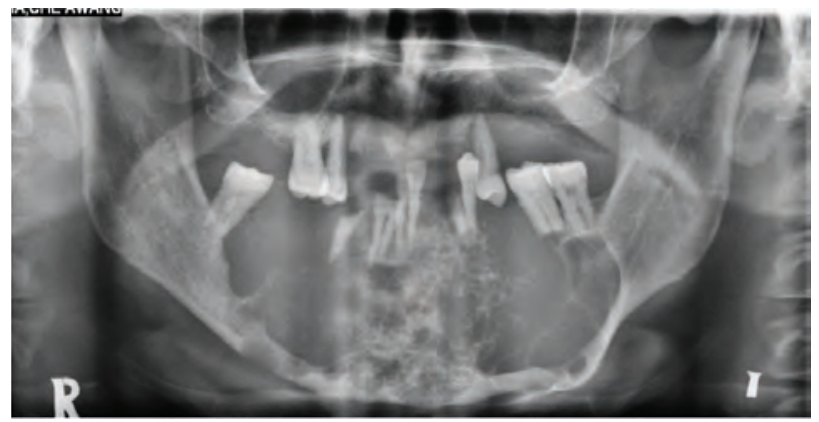

Figure 4. Orthopantomogram radiograph showing extension of the lesion. 


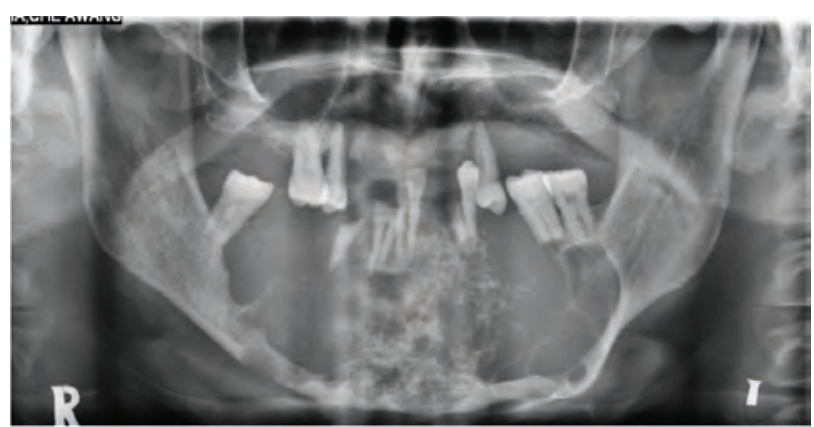

Figure 4. Orthopantomogram radiograph showing extension of the lesion.

showed the lesion is confined to the mandible. CT guidedpercutaneous lung biopsy was done. It showed no ameloblastic carcinoma cells on the left upper lobe. Fine needle aspiration cytology of the palpable lymph nodes was done. That showed ameloblastic cells infiltration. TNM staging T4N2bM0

Based on these findings, the diagnosis was ameloblastic carcinoma and the differential diagnosis was intraosseous carcinoma, squamous odontogenictumour, calcifying epithelial odontogenic tumour, salivary gland neoplasia or other metastatic carcinoma to the jaws from other primary locations. Histopathology

Incisional biopsy revealed the tumour was composed of islands and sheets of odontogenic epithelium exhibiting basal cell palisading and hypercellular stellate reticulum like cells having vacuolated nuclei with prominent nucleoli. The periphery of cells nests exhibited a columnar morphology. These cells contained pleomorphic nuclei with mitotic figures. Squamous metaplasma together with infiltrating well-differented squamous cell carcinoma islands were present in these areas (Figure 6 a-d)

\section{Treatment}

Surgical excision ( $2 \mathrm{~cm}$ clear margin) with primary reconstruction of the defect was the mode of treatment chosen for this patient (Figure 7).Tracheostomy and reconstruction with osteomyocutanous free fibula flap was planned. The mandible was resected from the right body to the left body preserving both condyles. All the upper teeth which had poor prognosis and retain roots were also extracted. Right functional neck dissection and left supraomohyoid dissection was done.

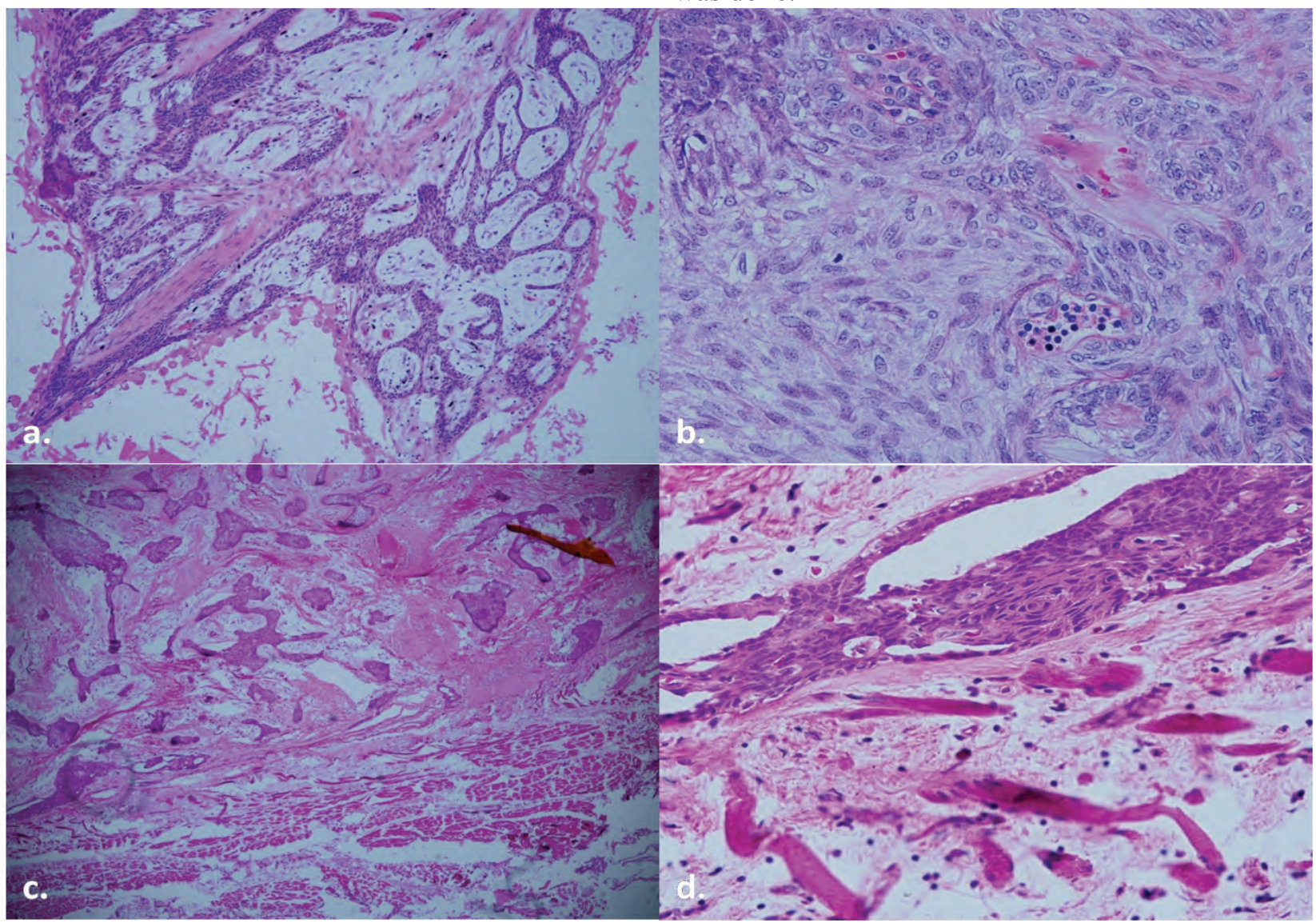

Figure 6. Histopathology: a. Sheets of odontogenic epithelium with palisading basal cell and hypercellular stellate reticulum like cells with vacuolated nuclei. b. Higher magnification showing cells containing pleomorphic nuclei with mitotic figures. c. Squamous cell metaplasia with infiltrating squamous cell carcinoma. d. Higher magnification showing tumour infiltrating the muscle tissues. 
A $23 \mathrm{~cm}$ length fibula graft with overlying skin was harvested from the right leg. The fibula graft was fixed with the mandible with reconstruction plates and titanium screws. The vessels were anastomosed to the facial artery and veins while the skin from the dorsum of the thigh was used to provide the intraoral cover. Nasogastric tube was inserted to facilitate feeding (Figure 8). The graft and donor site healed without any complications (Figure 9). PostoperativeOrthopanthomogram radiograph shows two reconstruction plate with the fibula graft (Figure 10). The resected mandible and lymph nodes were sent for histopathological study. The results confirmed our diagnosis of ameloblastic carcinoma with $2 \mathrm{~cm}$ clear margin of the lesion and the remaining lymph nodes free from any lesions.

The patient was sent for radiotherapy after 4 weeks to eliminate any residual cancer cells. The dose given was 60 Gy over a 6 weeks period with radiation 5 days a week. Post radiation shows area of fibrosis on the right and left neck area (Figure 11 and 12). Noted

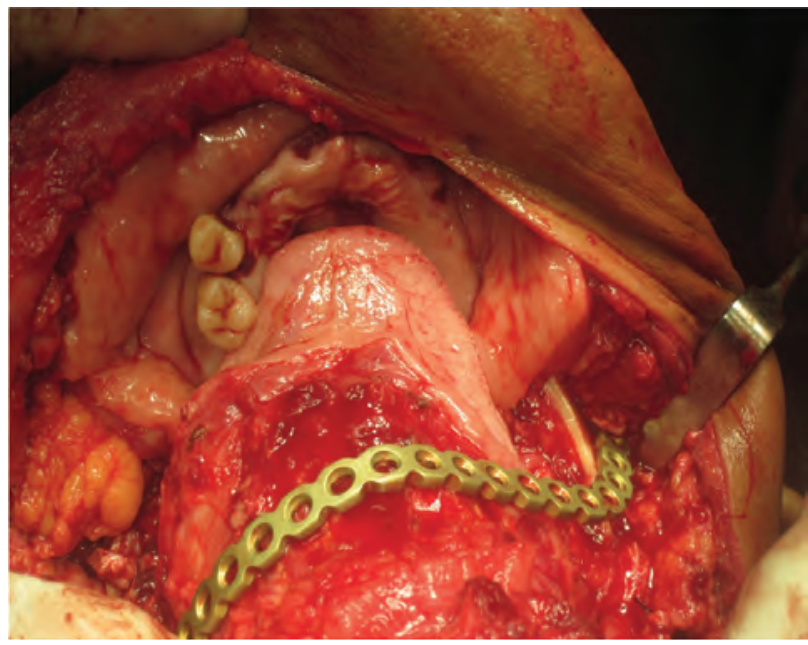

Figure 7. M andible resected and recon plate being contoured.

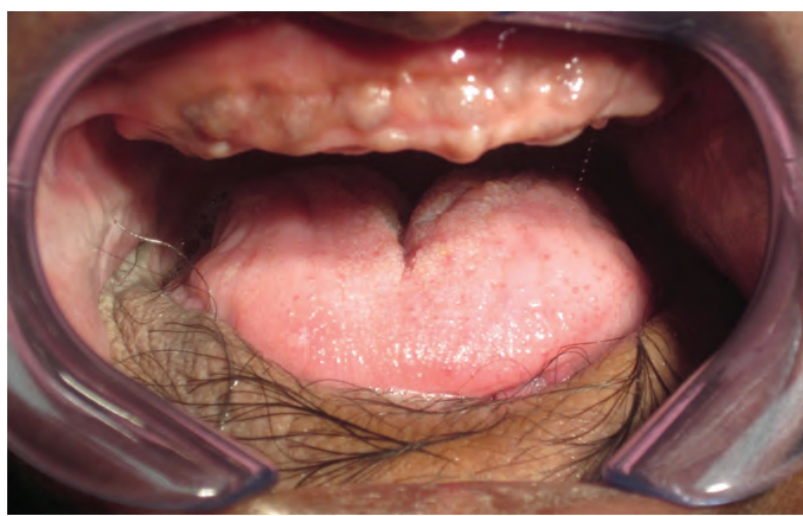

Figure 9. Intra oral view of the reconstructed flap and skin cover. wound breakdown on left side of the neck (Figure 12). The breakdown was managed by daily dressing and cleaning with chlorhexidine solution weekly. The wound healed uneventfully. He also complained about the hair growth intraorally which was trimmed regularly. Retrospectively a skin graft from non- hair bearing area might have avoided this problem.

After six months, the patient was fitted with upper and lower full dentures. He is able to lead a reasonable normal life after the rehabilitation.

After 2 years our patient continues to remain free of local, regional or distant metastasis as he remains on active follow-up with periodic radiographic follow up (Figure 13).

\section{Discussion}

Our patient was diagnosed as having pulmonary tuberculosis one year before seeing us. As a consequence, the lesion seen in the chest radiograph (Figure 5) and the palpable lymph node could be also due to the metastasis or pulmonary tuberculosis. Datta et $\mathrm{al}^{8}$ have mentioned that ameloblastic carcinoma is

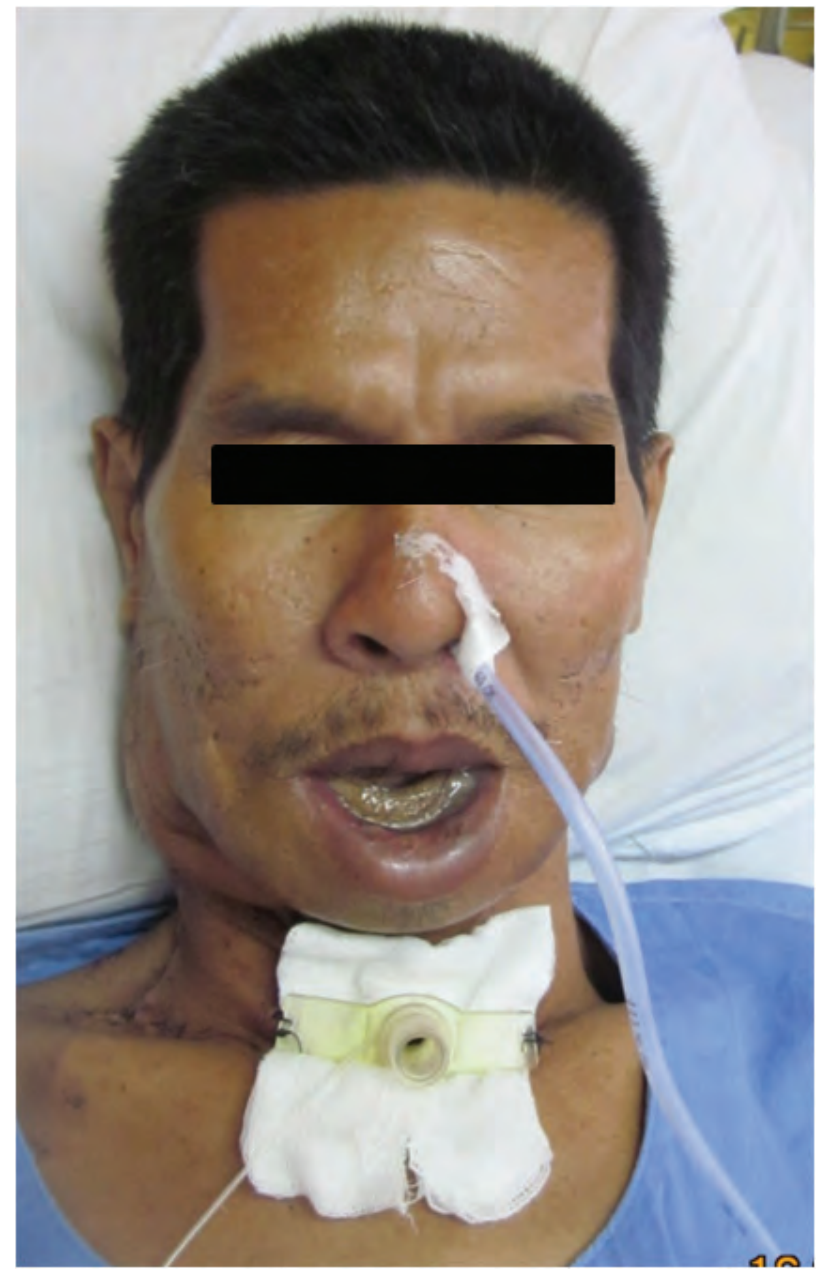

Figure 8. Immediate post op view with tracheostomy and Nasogastric tube. 


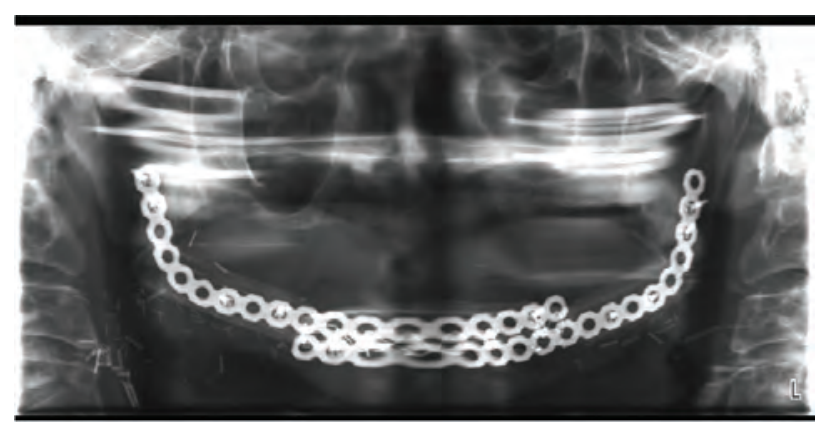

Figure 10. Post surgery OPG with two reconstruction plate and the fibula graft.

an aggressive neoplasm that is locally invasive and can spread to regional lymph nodes or distant sites such as lungs and bones. Fine needle aspiration cytology confirmed the palpable lymph nodes were infiltrated with ameloblastic cells and biopsy of the lungs showed no ameloblastic cells in the lungs. Even though this case demonstrated unusual spread within short period time (6 months), we had to delay the treatment because of the patient's pulmonary tubercolosis. We waited until his sputum tests were negative for 3 consecutive weeks before doing the operation to reduce the chances of cross infection.

The diagnosis criteria of ameloblastic carcinoma from ameloblastoma or malignant ameloblastoma are based on cytologicatypia and increased mitotic activity. ${ }^{9}$ Most ameloblastic carcinoma arise de novo and less than $1 \%$ of ameloblastoma undergo

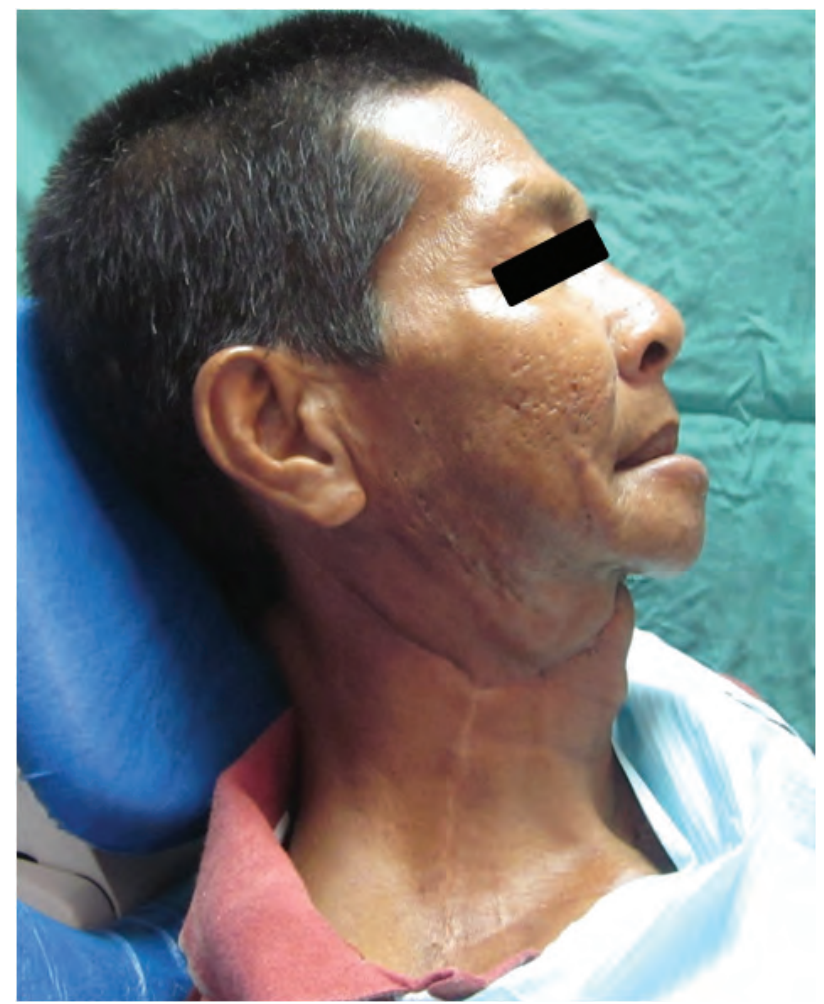

Figure 11. Post radiation right side of the neck. malignant transformation. ${ }^{10}$ Some studies have recorded widespread metastatsis to the lung, bones through lymphatics and bloodstream. ${ }^{11,}{ }^{12}$ These lesions should be distinguished from metastatic ameloblastoma which is defined as a histoloigical benign appearing ameloblastoma with metastasis.

From the differential diagnosis, intraosseous carcinoma is difficult to differentiate radiographically, histologically or clinically from ameloblastic carcinoma. In fact the intra osseous carcinoma may represent a less differentiated non keratinizing form of ameloblastic carcinoma both being deprieved from odontogenic epithelial remants. ${ }^{3,13}$ Nonethess, typical features of ameloblasticdfferentiation which would justify a diagnosis of ameloblastomic carcinoma are usually lacking in intraosseous carcinoma. ${ }^{14}$ Squamous odontogenic tumour is composed of islands of squamous cells and epithelial odontogenic tumour contains sheets of epithelial and amyloid like material with concentric ring calcification which can differentiate it from ameloblastic carcinoma. Salivary gland neoplasm or secondary from other sites may invade the jaws and can be differentiate from the history and clinical symptoms. ${ }^{15,16}$ Marsuzaki et al ${ }^{17}$ have reported that immunohistochemistry study of ameloblastic carcinoma will reveal high positive rates of P53 and Ki67 to aid in the diagnosis of this lesion. Chromosal imbalances in ameloblastomawhith losses in choromsoam 22 and 10 have been reported.

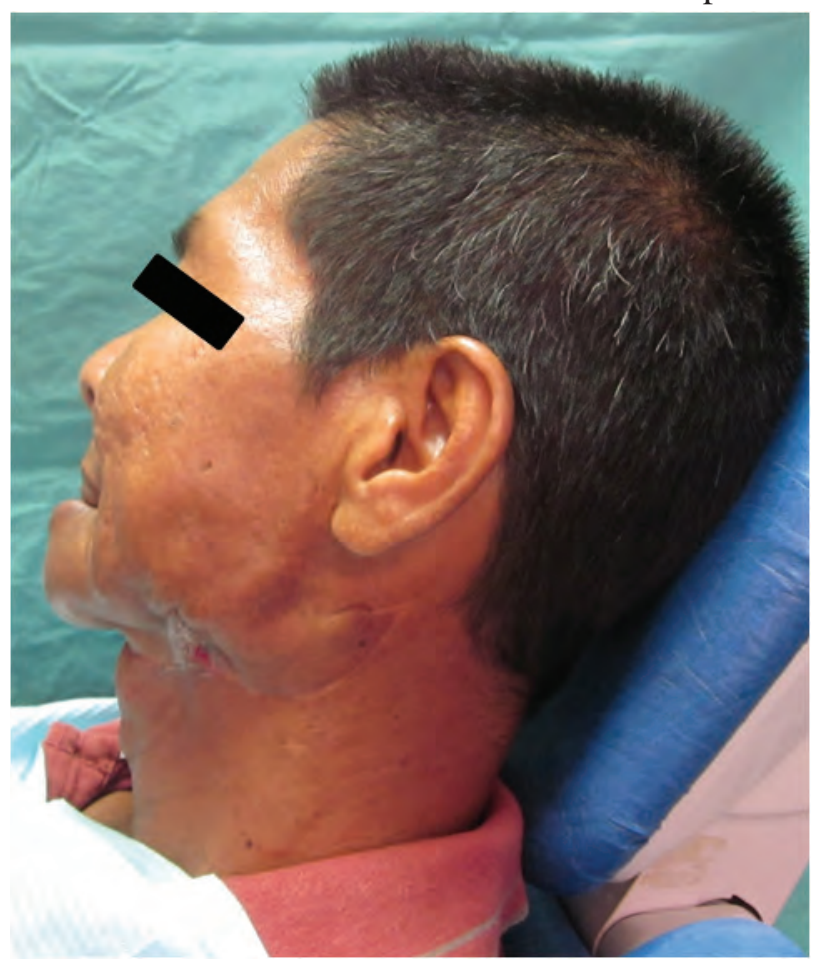

Figure 12. Left side of the neck post radiation. Wound breakdown noted at angle of the mandible. 
In additional to that aneuploidy is more common in ameloblastic carcinoma and may predict its malignant potential. ${ }^{18}$

In our patient, the histology showed features of malignancy like higher mitotic activity, ell atyplia, hyperchromatic nuclear, invasion of bone and muscles. Clinically ameloblastoma have a slow growth with 27 months as the mean duration before any symptoms. ${ }^{19}$ This case shows growth in only 6 months. Moreover there is perforation of the cortex of mandible intraorally. Ameloblastoma hardly perforates the cortex unless left undetected for a very long time. Pain and parathesia is also not a common finding in ameloblastoma. ${ }^{19}$ From the demographics, the mean age for ameloblastic carcinoma is 52, male to female ratio is $2: 1$ and $66 \%$ of the times the lesion is located in the mandible. ${ }^{7}$ This information is consistent with our patient presented here.

Most of the cases of ameloblastic carcinoma in the literature was treated with extensive surgery with margins of 2-3 cm. Radiotherapy was used after the surgery for cases with close resection margin, extracapsular or perineural invasion. ${ }^{6,20,21}$ Chemotherapy did not show any promising results. ${ }^{6}$, ${ }^{22}$ Radiotherapy alone is also not recommended given its intraosseous location. ${ }^{23}$ Recently Perera et al. have reported on the use of gamma knife stereotatic radiosurgery in the management of recurrent ameloblastic carcinoma lesion. The authors showed promising results for recurrent lesions after 2 years of post-resection. Based on the above information, we decided surgical option with concomitant radiotherapy. We managed to preserve the condyle in this patient. Keeping the mandibular condyle allows the patient to preserve the temporo- mandibular joint which gives better mobility to the rest of the jaws and also diminishes post-op pain.

The task of restoring the mandibular defect is a challenging problem for surgeons after ablation of the tumour. Microvascular techniques to transfer vascularized bone to the head and neck region have been successfully applied to solve the problem of various segmental mandibular defects. ${ }^{24,}{ }^{25}$ In our case, almost the entire mandible was successfully reconstructed with a vascularised fibula flap.

Local recurrence have been reported between 5 to 151 months. ${ }^{20,} 26$ Distant metastasis has also been reported as early as 4 months and as late as 47 months after surgery. ${ }^{20,} 27$ Therefore long term follow-up is mandatory to detect the late recurrence or metastasis. The 5 and 10 year survival rates were $72.9 \%$ and $56.8 \%$ respectively. ${ }^{21}$ It is important that people should be fortified to immediately report to a surgeon whenever they see any unusual swelling any discomfort. Management should also include the awareness of the people of their responsibilities regarding their own health, and not wait for the swelling to grow and cause great discomfort and difficulty to themselves in future. ${ }^{28}$ Nonetheless, it is generally known that there were significant association between histological subtype and recurrence outcome and between treatment and recurrence of ameloblastoma. ${ }^{29}$

\section{Conclusion}

Ameloblastoma shows a spectrum of histology and biologic behaviour ranging from benignity at one end to malignancy at the other end. Cases of ameloblastoma should thus be carefully analysed to detect subtle changes in the histology that may predict its aggressive behaviour. We have reported a rare case of primary ameloblastic carcinoma of the mandible in a 53 year old man. Aggressive wide excision and radiotherapy with primary reconstruction has given a successful outcome. However long term follow up is necessary to detect the late recurrence or metastasis.

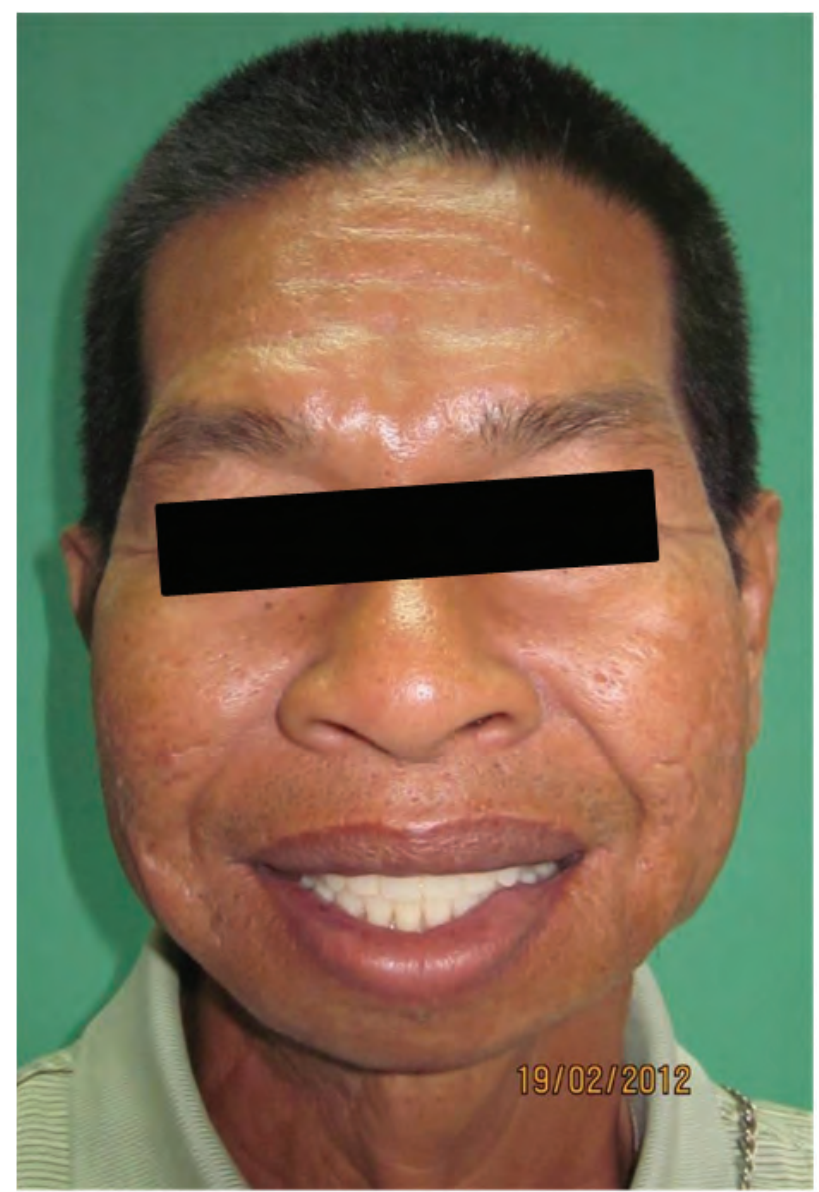

Figure 13. After 2 years follow up review.

Conflict of interest: None declared. 


\section{References}

1. Shafer WG, Hine MK, Levy BM. A textbook of Oral Pathology. Philadelphia: PA Saunders; 1983.

2. Neville BW, Damm DD, Allen CM, Bouquot JE. Oral and maxillofacial pathology. 2 ed. Philadelphia: WB Saunders Co.; 2002.

3. Corio RL, Goldblatt LI, Edwards PA, Hartman KS. Ameloblastic carcinoma: a clinicopathologic study and assessment of eight cases. Oral Surg Oral Med Oral Pathol 1987;64(5):570-6.

4. Dorner L, Sear AJ, Smith GT. A case of ameloblastic carcinoma with pulmonary metastases. $\mathrm{Br} J$ Oral Maxillofac Surg 1988;26:503.

5. Karakida K, Takahashi M, Sekido Y. Ameloblastic carcinoma, secondary type: a case report. Med Oral Pathol Oral Radiol Endod 2010;110:e33-e37.

6. Benlyazid A, Lacroix-Triki M, Aziza R, Gomez-Brouchet A, Guichard M, Sarini J. Ameloblastic carcinoma of the maxilla: case report and review of the literature. Oral Surg Oral Med Oral Pathol Oral Radiol Endod 2007;104(6):e17-24.

7. Akrish S, Shoshani Y, Dayan D. Ameloblastic Carcinoma: Report of a New Case, Literature Review and Comparison to Ameloblastoma. J Oral Maxillofac Surg 2007;65:77783.

8. Datta R, Winston JS, Diaz-Reyes G, Loree TR, Myers L, Kuriakose MA, et al. Ameloblastic carcinoma: report of an aggressive case with multiple bony metastases. Am J Otolaryngol 2003;24(1):64-9.

9. Slater LJ. Odontogenic malignancies. Oral Maxillofacial Surg Clin N Am 2004;16:409.

10. Yoshioka Y, Ogawa I. Ameloblastoma Carcinoma, Secondary Type, of the Mandible: A Case Report. J Oral Maxillofac Surg 2013;71:e58-e62.

11. Dhir K, Sciubba J, Tufano RP. Ameloblastic carcinoma of the maxilla; Report of an aggressive case with multiple bony metastases. Oral Oncol 2003;39:735.

12. Data R, Winstron JS, Diaz-Reyes G. Ameloblastic carcinoma: Report of an aggressive case with multiple bony metastases. Am J Otolaryngol 2003;24:64.

13. Avon SL, Mc Comb J, Clokie C. Ameloblastic carcinoma: case report and literature review. J Can Dent Assoc 2003;69:573-76.

14. Elzay RP. Primary intraosseous carcinoma of the jaws. Review and update of odontogenic carcinomas. Oral Surg Oral Med Oral Pathol 1982;54(3):299-303.

15. Simko EJ, Brannon RB, Eibling DE. Ameloblastic carcinoma of the mandible. Head Neck 1998;20:654-59.
16. Matear DW, Crewe TC. Malignant Ameloblastoma? A case report and review of literature outlining problem in diagnosis and treatment. J R Nav Med Serv 1991;77:5-10.

17. Matsuzaki H, Asaumi J, Hisatomi M, Nagatsuka H. Ameloblastic carcinoma: a case report with radiological features of computed tomography and magnetic resonance imaging and positron emission tomography. Oral Surg Oral Med Oral Pathol Oral Radiol Endod 2011;112:e40-e47.

18. Nodit L, Barnes L, Childers E, Finkelstein S, Swalsky $\mathrm{P}$, Hunt J. Allelic loss of tumour suppressor genes in ameloblastic tumours. Mod Pathol 2004;17:1062-7.

19. Reichart PA, Philipsen HP, Sonner S. Ameloblastoma: Biological profile of 3677 cases. Oral Oncol Eur J Cancer 1995;31B:86.

20. Hall JM, Weathers DR, Unni KK. Ameloblastic carcinoma: an analysis of 14 cases. Oral Surg Oral Med Oral Pathol Oral Radiol Endod 2007;103:799-807.

21. Yoon HJ, Hong SP, Lee SS, Hong SD. Ameloblastic carcinoma: an analysis of 6 cases with review of the literature. Oral Surg Oral Med Oral Pathol Oral Radiol Endod 2009;108:904-13.

22. Philip M, Morris CG, Werning JW, Mendenhall MW. Radiotherapy in the treatment of ameloblastoma and ameloblastic carcinoma. J HK Coll Radiol 2005;8:15761.

23. Small IA, Waldron CA. Ameloblastoma of the jaws. Oral Surg 1955;8:281.

24. Urken ML, Buchbinder D, Costantino PD, Sinha U, Okay D, Lawson W, et al. Oromandibular reconstruction using microvascular composite flaps. Arch Otolaryngol Head Neck Surg 1998;124(1):46-55.

25. Cordeiro PG, Disa JJ, Hidalgo DA, Hu QY. Reconstruction of the mandible with osseous free flaps: 10 year experience with 150 consecutive patients. Plastic Reconstr Surg 1999;104(5):1314-20.

26. Lee L, Maxymiw WG, Wood RE. Ameloblastic carcinoma of the maxilla metastatic to the mandible. Case report. $J$ Craniomaxillofac Surg 1990;18:247-50.

27. Bruce RA, Jackson IT. Ameloblastic carcinoma. Report of an aggressive case and review of the literature. $J$ Craniomaxillofac Surg 1991;19(6):267-71.

28. Malik SN, Alam MK, Shahina M, Siddique S, Prabhu VD. Calcifying epithelial odontogenic tumor (CEOT) - A Review. Bangladesh J Med Sci. 2014;13(1):14-19.

29. Ismail R, Pohchi A, Rajion ZA, Rahman RA, Alam MK. Ameloblastoma at Hospital Universiti Sains Malaysia (HUSM): A Fifteen Year Retrospective Study. Int Med J. 2014;21(1):113-116. 